Article

\title{
Drivers of Change in National Disaster Governance under the Hyogo Framework for Action
}

\author{
Maximilian S. T. Wanner ${ }^{1,2}$ \\ ${ }^{1}$ Department of Government, Uppsala University, 75120 Uppsala, Sweden; E-Mail: maximilian.wanner@statsvet.uu.se \\ 2 Centre of Natural Hazards and Disaster Science, Uppsala University, 75236 Uppsala, Sweden
}

Submitted: 30 March 2020 | Accepted: 10 May 2020 | Published: 10 December 2020

\begin{abstract}
Many suggestions have been made on what motivates countries to expand their measures for disaster risk reduction (DRR), including the frequency and severity of natural hazards, accountability mechanisms, and governance capacity. Despite the fact that theoretical arguments have been developed and evidence collected from small-scale case studies, few studies have attempted to explain the substantial variation in the adoption of DRR measures across countries. This study combines available data on DRR measures, natural hazard events, governance, and socioeconomic characteristics to provide a systematic assessment of the changes that have occurred in the state of DRR at the national level. In line with theoretical explanations, there are indeed associations between several measures of frequency and severity and the development of DRR status. Additionally, voice and accountability mechanisms, as well as development aid, might facilitate positive change. Although these first results of a global comparative study on change in DRR have to be taken cautiously, it is a step forward to understanding the drivers of change at the national level.
\end{abstract}

\section{Keywords}

accountability mechanisms; climate change adaptation; disaster governance; disaster risk reduction; Hyogo Framework for Action; policy change; punctuated equilibrium

\section{Issue}

This article is part of the issue "The Politics of Disaster Governance" edited by Dorothea Hilhorst (Erasmus University Rotterdam, The Netherlands), Kees Boersma (Vrije Universiteit Amsterdam, The Netherlands) and Emmanuel Raju (University of Copenhagen, Denmark).

(C) 2020 by the author; licensee Cogitatio (Lisbon, Portugal). This article is licensed under a Creative Commons Attribution 4.0 International License (CC BY).

\section{Introduction}

Little is known about the way in which and the reasons why national action on disaster risk reduction (DRR) has changed globally. This is despite the acknowledgement that a shift has occurred, towards more proactive attention, in light of the two prominent UN-led frameworks, the Hyogo Framework for Action (HFA) and the Sendai Framework for Disaster Risk Reduction established in 2005 and 2015, respectively. It is also despite the increasing losses connected to natural hazards in recent decades due to a rise in their frequency and severity (Di Baldassarre et al., 2018).

While several studies have investigated changes in policy and adoption of DRR measures at the local and sub-national level, data provided by the United
Nations Office for Disaster Risk Reduction (UNDRR, formerly United Nations International Strategy for Disaster Reduction) enable such analysis of national action at the global scale. We have recently explored the patterns of progress under the HFA and expounded the progress achieved (Wanner, 2020); however, as of yet, we have not been able to empirically ascertain the factors that drive progress towards a higher level of DRR globally. Since such changes in DRR measures represent a form of policy development, established theoretical models of policy change, including incrementalism and punctuated equilibrium theory, can be used to study potential explanations in the field of DRR.

Thus, this study sets out to investigate the relation between the changes in the national status of DRR measures under the HFA and the most prominent theories 
of policy change in an attempt to explain the substantial variation across countries. Whereas the HFA covers all kinds of hazards - technological and natural alike-this study focuses specifically on the effect of natural hazard events because of the aforementioned increase in their frequency and impact over recent decades. To this end, data on DRR measures, natural hazard events, and governance are combined for a systematic assessment of the change in the status of DRR measures at the national level.

Consequentially, this article statistically tests the theoretical explanations for DRR policy change proposed by previous literature. Potential explanations to be tested include incremental changes and external shocks operationalised as the increasing frequency and severity of natural hazards over recent years, as well as the prospect of politicization of hazard events. This study is the first attempt of a global assessment of change in national DRR, providing the opportunity to learn more about the patterns of progress in DRR and contribute to the understanding of the evolution of DRR measures.

\section{Drivers of Change in National Disaster Governance}

By experiencing hazardous or disastrous events, authorities might learn how to adapt to and prepare for similar occurrences in the future. They might incrementally adopt new measures to adapt to changing circumstances or introduce changes in response to specific, large-scale events. In addition, the politicisation of the event and its consequences might even facilitate or impede the development of DRR measures. In the field of DRR and disaster governance, we have not yet systematically investigated any of the potential explanations on a larger scale, most likely because of the scarcity of appropriate data. Below, we outline the predominant yet potentially competing theoretical approaches that have been established within research on policy change in the context of crises and disasters.

On one side, incrementalists would argue that policy development and implementation is usually a process whereby small changes gradually accumulate (Hayes, 2017; Lindblom, 1959; Pierson, 2000). In the case of DRR, this idea is inherently connected to the idea of adaptation to frequent or intensifying natural hazard events. Most commonly, these hazards tend to re-occur in the same area allowing stakeholders to learn, and prepare for, potential future events. Thus, when hazards frequently occur and only increase slightly in their magnitude, rather incremental changes might be established to adapt to the threat and minimise future losses (Nohrstedt \& Nyberg, 2015). Previous findings from studies on cases on the sub-national level and single hazards suggest that hazard frequency and repetitive damage play a significant role because of raised awareness or growing pressures (Brody, 2003; Brody, Zahran, Highfield, Bernhardt, \& Vedlitz, 2009; Muller \& Schulte, 2011; Russell, James, \& Bourque, 1995).
In stark contrast to incrementalism, the theory of punctuated equilibrium argues that external shocks, which fall outside the range of normal and expected disturbances, drive changes in policy and measures that are adopted (Baumgartner, Jones, \& Wilkerson, 2002; Jones \& Baumgartner, 2012; Krasner, 1984). When hazards turn into disasters due to large-scale human or capital losses, they represent external shocks or focusing events disrupting the established system and potentially leading to substantial change following a spike in attention and pressure to reform (Birkland, 2016; Dekker \& Hansén, 2004; Olson, 2000). Whether it is the number of people killed and injured (Zahran, Brody, Vedlitz, Grover, \& Miller, 2008) or financial losses (Brody et al., 2009), studies have identified that the potential of impacts of hazards are drivers of change in local-level case studies. Others have pointed out that frequent but low-impact events can lead to adverse developments due to a 'normalization bias' (Mileti \& Brien, 1992) for non-victims.

Thus, natural hazards can be understood as drivers of change in DRR measures from both perspectives, incrementalism and punctuated equilibrium, or as a combination or synthesis of them (Collier \& Collier, 1991; Stark, 2018). Both the frequency and severity of natural hazards may play a major role in the change in the level of DRR measures. However, we need to consider that continuing disturbances might act as hindrances by overburdening the governmental apparatus since the system might be unable to handle the situation. Therefore, the governance capacity comprising governance structures, coordination, human resources, and the assignment of roles and mandates might be crucial for determining whether the frequency of natural hazards affects the national level of DRR measures (Koivisto \& Nohrstedt, 2017).

As mentioned before, hazard events tend to get politicised very quickly in a political game of framing and blaming, finger-pointing and assigning responsibility (Boin, 't Hart, \& McConnell, 2009; Olson, 2000). While there is reason to assume that the windows of opportunity for change and reform are smaller than expected due to barriers in crisis management (Boin \& 't Hart, 2003, 2010), framing, agenda-setting, and accountability mechanisms might also enable political action and change-not only in government but also in policy implementation. To transpose Amartya Sen's logic of famines and democracy to DRR, the citizenry is unlikely to re-elect or support officials who do not act to avoid or ameliorate future impacts (Sen, 2001). Because citizens transfer responsibility to the authorities (Adger, Quinn, Lorenzoni, Murphy, \& Sweeney, 2013), these mechanisms ensure that politicians acting against the interest of the citizens will have to leave office. Accordingly, when many people are affected by natural hazards and are in favour of more expansive DRR measures, authorities would be more likely to opt to increase DRR measures. A recent study on the reduction of nuclear power after the Fukushima meltdowns supports the positive impact of civil liberty 
rights and accountability mechanisms on policy change after a disaster (Aldrich, Forester, \& Horhager, 2019).

In sum, the study of change in the national status of DRR measures will focus on three potential explanations: incremental change, external shocks, and accountability mechanisms. Consequentially, the analysis will explore the relations of adopted DRR measures, the frequency and magnitude of natural hazards, and governance characteristics. Thereby, it is expected that all of these might facilitate the expansion of DRR measures to some extent.

\section{Data and Research Methodology}

\subsection{Dependent Variable}

Change is central since the status of DRR measures does not provide any information about what led to the actual measures at specific points in time. Hence, the empirical evaluation focuses on the change in the status of national DRR measures from one period to the next in the attempt to find explanations for the differences in change between countries.

The data for the dependent variable comes from PreventionWeb, a website hosted and managed by the UNDRR (formerly United Nations International Strategy for Disaster Reduction), which was in charge of the HFA and collected the national reports (UNDRR, n.d.). The UN framework ran between 2005 and 2015 with its ultimate goal being to substantially reduce disaster losses by 2015 (United Nations International Strategy for Disaster Reduction, 2005). The data are based on voluntary country reports on the status of DRR measures and comprises 22 key activities sorted into five priorities for action (see the Supplementary File for full list). The status is mea- sured on an ordinal five-point scale spanning the following categories: (1) minor progress with few signs of action in planning or policy; (2) some progress, but without systematic policy and/or institutional commitment; (3) institutional commitment attained, but achievements being neither comprehensive nor substantial; (4) substantial achievement attained but with recognized limitations in key aspects, such as financial resources and/or operational capacities; and (5) comprehensive achievement with sustained commitment and capacities at all levels.

The reports further include qualitative and quantitative questions on the key activities that informed the categorisation. Although the categories are described in terms of progress, this is rather misleading since they rather capture the status of DRR measures at one point in time without integrating the change in respect to previous periods.

The unit of analysis of this study is country-reporting period, ideally, resulting in four observations per country. The change in the status of DRR measures is then the averaged net change in the 22 key activities from one reporting period to the next. For this, the analysis interprets the ordinal scale as quasi-interval only for the purpose of summarising the status of DRR measures. Because distances on the scale remain opaque and uninterpretable between countries, the scale of the dependent variable is again turned into an ordinal scale differentiating categories by the direction and magnitude of change, since the additional information created is not reliable across countries. Due to the distribution of observations, the categories were created representing negative, negligible, and positive change. Thereby, the thresholds were set at one standard deviation of the mean. Figures 1 and 2 both depict the distribution into cate-

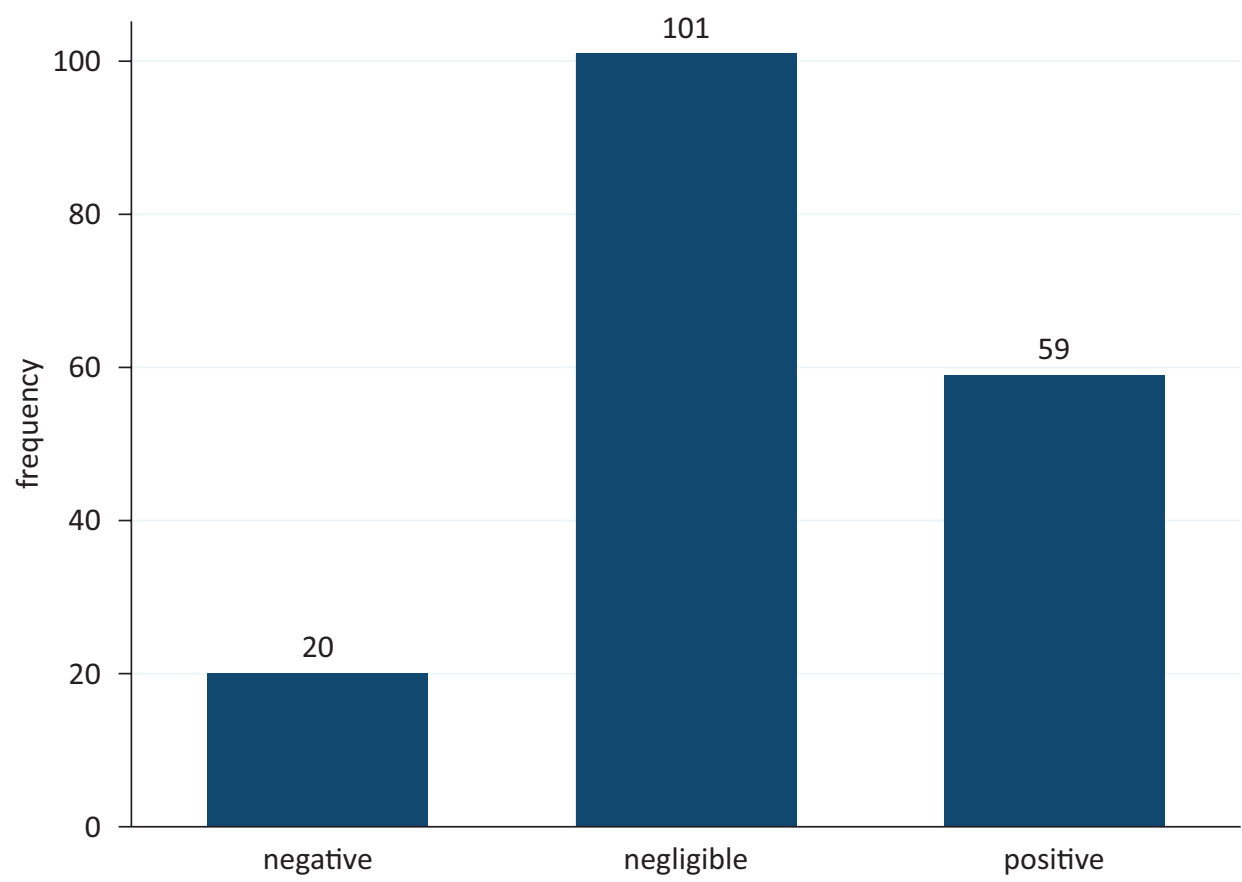

Figure 1. Distribution into 3 categories after collapsing (Stata). 


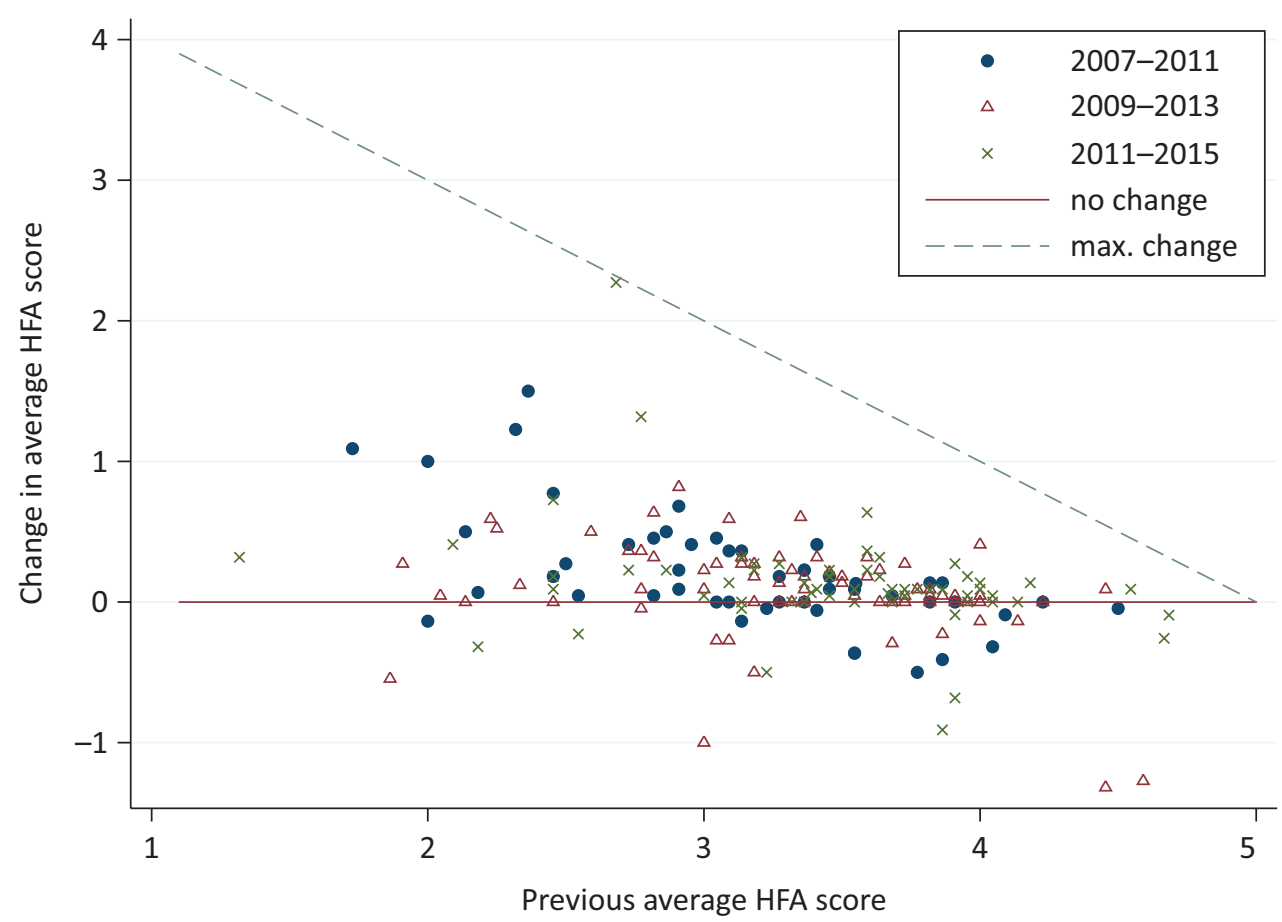

Figure 2. Change in aggregated scores for each country from one period to the next. Notes: Dashed line $=$ maximal positive change possible. Solid line $=$ no change reference line (Stata).

gories and the empirical data on changes in the status of DRR measures.

Considering the scale of the dependent variable, ordered logit models are employed given the quality of the information in order to obtain meaningful results (Long \& Freese, 2014). In particular, generalised ordered logit models were used because of the theoretically expected asymmetrical effects and-by the Brant testempirically detected violations of the assumption of parallel lines or proportional odds (Brant, 2016; Fullerton \& Dixon, 2010; Williams, 2016). Therefore, the Stata program gologit2 provided by Williams $(2006,2016)$ is utilised, which enables one to relax the assumption of parallel lines. This means that the effects of some or all predictors are allowed to vary depending on the value or category of the dependent variable. For instance, for the effect of the number of occurrences, it may make a difference whether a country falls into the negative or positive category. This allows one to potentially make observations such as higher levels of occurrence can hamper progress if a country is in the negative change category, but facilitate progress if a country is in a higher category.

Results have to be handled with caution since the analysis might be distorted because of state-dependent reporting biases or reporting heterogeneity, i.e., that countries differently interpret the thresholds or cutoff points on the ordinal scale measuring the level of the DRR activities (Lindeboom \& Van Doorslaer, 2004), "making policy recommendations unreliable" (Schneider, Pfarr, Schneider, \& Ulrich, 2012, p. 251). Since observations are considered independent across countries and to account for dependencies within countries, clustered standard errors are always used.

\subsection{Explanatory Variables (Predictors)}

In order to capture the possible relationships between the change in the status of DRR measures and potential explanations, the HFA data are matched with several other datasets. The predictors are based on the potential drivers of change suggested by previous research. The theoretical ideas of incrementalism, punctuated equilibrium, and politicisation are operationalised in predictors comprising different measures of the frequency and severity of natural hazards as well as governance characteristics.

Data on the frequency and severity of natural hazards are taken from the Emergency Event Database (EM-DAT), which is the International Disaster Database provided by the Centre for Research on the Epidemiology of Disasters hosted at the Université Catholique de Louvain. Since it is indeed a global database with country-level data on natural and technological disasters "containing...data on the occurrence and effects of...disasters in the world, from 1900 to present" (Centre for Research on the Epidemiology of Disasters, 2009), only natural hazards according to their disaster group are considered with the exclusion of biological hazards. As mentioned before, natural hazards are in the spotlight of this analysis due to their increasing frequency, intensifying circumstances, and rising losses (Di Baldassarre et al., 2018). As there are alternative approaches to measuring the frequency 
and severity, this study considers the pure number of occurrences as the measure of frequency. It should be mentioned that EM-DAT only includes events that fulfil at least one of the following criteria: 10 or more people dead, 100 or more people affected, declaration of a state of emergency, or a call for international assistance (Centre for Research on the Epidemiology of Disasters, 2009). As such, neither small-scale events nor large-scale events with only financial damage are covered. Following the logic presented before, the interaction with governance capacity will be included in the analysis, because this capacity may indicate whether the authorities were overburdened by the situation. Thus, it would be an indication for incremental change, if there is a positive association between (1) the interaction of recent occurrences and government capacity and (2) DRR status being in the positive change category.

Concerning the severity, the statistical analysis includes several measures, namely financial damage, death toll and the number of people affected, since either of them is sufficient for an event being classified as a shock. They are all put in relation to historical measurements over the 20 years before the HFA to detect uncommon spikes, representing extraordinary shocks to the system.

The number of the affected was also put in relation to the total population and, then, interacted with the index of voice and accountability. This represents the politicization of hazardous events in line with Sen's logic. The reasoning is that the larger the proportion of the population affected and the more rights citizens have to voice their opinion and hold authorities responsible, the more likely it is that there will be a positive change.

The data on government capacity, accountability mechanisms, and education stems from the World Bank but was taken from the Quality of Governance Standard Data (QOG) provided by the Quality of Government Institute at the University of Gothenburg. This data is a collection of national data on governance and governments from more than 100 data sources (Teorell et al., 2020b). The analysis in the article includes the index of Voice and Accountability (wbgi_vae) because it best reflects "the extent to which citizens of a country are able to participate in the selection of governments" (Teorell et al., 2020a, p. 619), as well as the index of Governance Effectiveness (wbgi_gee) as a measure of governance capacity.

\subsection{Control}

In addition to the predictors, there is a need to include several controls that might have an impact on the dependent variable. First, a lagged variable as a control capturing the previous level of DRR measures has to be introduced. This is necessary since it substantially affects the possibility for change in the next period because of the rigid ordinal five-point scale of the HFA. Second, historical data on death tolls, financial damage, and number of people affected were included to control for historical effects and the hazard history of the country. Multicollinearity was detected between recent and historical data; however, since they account for different explanations, they were not excluded (see the Supplementary File for correlation table).

Third, total official development aid (ODA) was included as a control to account for financial capacities. Additionally, a measure of relational ODA (ODA in the period in relation to the average of the previous three years) was added to account for spikes or drops in aid. Fourth, a control was added for the number of reports submitted by a country, since engaged countries might follow the HFA guidelines more thoroughly. This is related to theories on the diffusion of knowledge and best practices, which was facilitated by the arenas established by the UN frameworks. Fifth, controls for education were included on primary and secondary levels. Lastly, measures of the state of development, i.e., GDP/cap, were excluded since strong collinearity with the governance indices was detected. Table 1 below provides the summary statistics, sources, and linked theoretical perspectives of the various variables.

\section{Results}

This section presents the results in the following subsections. First, the statistical analysis of the HFA starting values is presented. Second, the relationship between the change in the status of DRR measures and the potential drivers are explored for three categories of change (negative, negligible, positive).

\subsection{HFA Starting Values}

A linear ordinary least square regression was conducted to check correlations and potential explanations for the starting values within the HFA. This was necessary to reveal biases in the data, i.e., conditions that led to higher starting values in a subset of countries.

As the results of four different models in Table 2 show, only country characteristics seem relevant for the national starting values. Government effectiveness or the level of development, which correlate, contribute to a higher starting value of the status of DRR measures. Thus, developing countries started at lower values than industrialised countries-everything else being equal. The results further indicate that countries with higher wealth and secondary school enrolment rates are more likely to be associated with a higher status of DRR measures when countries began their reporting. ODA is indeed another factor that is positively related to the starting value, but the effect is only marginal. Surprisingly, measures of historic hazard characteristics are throughout not relevant for the status of DRR measures at the inception of the HFA. In conclusion, it seems that DRR is another development issue. High starting values are more prevalent in more developed countries, 
Table 1. Summary statistics.

\begin{tabular}{|c|c|c|c|c|c|c|c|}
\hline Variables & Theoretical concept & Source & Obs. & Mean & Std. dev. & Min. & Max \\
\hline Previous Status (lag1) & Mediating factor & UNDRR & 174 & 3.336 & 0.625 & 1.318 & 4.684 \\
\hline Occurrence & Incrementalism & EM-DAT & 148 & 9.074 & 12.01 & 1 & 76 \\
\hline Deaths (rel.) & Shock & EM-DAT & 146 & 0.477 & 1.413 & 0 & 9.737 \\
\hline Damage (rel.) & Shock & EM-DAT & 139 & 1.069 & 4.704 & 0 & 44.23 \\
\hline Affected (rel./pop) & Shock & EM-DAT & 146 & 0.067 & 0.213 & 0 & 2.219 \\
\hline Occurrences (historical) & Incrementalism & EM-DAT & 174 & 46.49 & 69.29 & 1 & 490 \\
\hline Deaths (hist.) (ts.) & Incrementalism & EM-DAT & 174 & 11.62 & 34.69 & 0 & 183.1 \\
\hline Damage (hist) (bil. US\$) & Incrementalism & EM-DAT & 174 & 12.38 & 50.94 & 0 & 436.9 \\
\hline Affected (hist.) (mil.) & Incrementalism & EM-DAT & 174 & 29.61 & 162.8 & 0 & 1235 \\
\hline $\begin{array}{l}\text { School Enrol. } \\
\text { (primary) (\%) }\end{array}$ & Control & QOG/World Bank & 148 & 103.8 & 10.45 & 69.79 & 142.2 \\
\hline $\begin{array}{l}\text { School Enrol. } \\
\text { (secondary) (\%) }\end{array}$ & Control & QOG/World Bank & 135 & 84.20 & 26.18 & 18.66 & 146.4 \\
\hline $\begin{array}{l}\text { Governance } \\
\text { Effectiveness }\end{array}$ & Mediating factor & QOG/World Bank & 168 & 0.184 & 0.908 & -1.44 & 2.220 \\
\hline Voice \& Accountability & Accountability & QOG/World Bank & 168 & 0.209 & 0.862 & -1.70 & 1.728 \\
\hline GDP/capita (ts. US\$) & Control & QOG/World Bank & 167 & 15.72 & 21.53 & 0.226 & 100.8 \\
\hline $\begin{array}{l}\text { ODA Development } \\
\text { Aid (ODA) }\end{array}$ & Control & OECD & 174 & 590.0 & 908.1 & -415.91 & 4676 \\
\hline ODA (rel.) & Control & OECD & 174 & 0.666 & 2.365 & -28.299 & 5.809 \\
\hline $\begin{array}{l}\text { Total \# reports submitted } \\
\text { by country }\end{array}$ & Control & UNDRR & 180 & 3.247 & 0.723 & 2 & 4 \\
\hline
\end{tabular}

Table 2. Results of the OLS regressions for the HFA starting value.

\begin{tabular}{|c|c|c|c|}
\hline Variables & HFA_av & HFA_av & HFA_av \\
\hline $\begin{array}{l}\text { Occurrences } \\
\text { (hist.) }\end{array}$ & $\begin{array}{c}0.003 \\
(0.003)\end{array}$ & $\begin{array}{r}-0.000 \\
(0.002)\end{array}$ & $\begin{array}{c}-0.000 \\
(0.002)\end{array}$ \\
\hline $\begin{array}{l}\text { Deaths (hist.) } \\
\text { (thousands) }\end{array}$ & $\begin{array}{c}-0.002 \\
(0.002)\end{array}$ & $\begin{array}{r}-0.000 \\
(0.002)\end{array}$ & $\begin{array}{c}0.000 \\
(0.002)\end{array}$ \\
\hline $\begin{array}{r}\text { Damage (hist.) } \\
\text { (billion US\$) }\end{array}$ & $\begin{array}{c}-0.000 \\
(0.004)\end{array}$ & $\begin{array}{c}0.001 \\
(0.002)\end{array}$ & $\begin{array}{c}0.001 \\
(0.002)\end{array}$ \\
\hline $\begin{array}{l}\text { Affected (hist.) } \\
\text { (million) }\end{array}$ & $\begin{array}{c}-0.000 \\
(0.000)\end{array}$ & $\begin{array}{c}0.000 \\
(0.000)\end{array}$ & $\begin{array}{c}0.000 \\
(0.000)\end{array}$ \\
\hline $\begin{array}{l}\text { School enrolment } \\
\text { Primary }\end{array}$ & & $\begin{array}{c}-0.012^{*} \\
(0.006)\end{array}$ & $\begin{array}{c}-0.011^{*} \\
(0.006)\end{array}$ \\
\hline $\begin{array}{l}\text { School enrolment } \\
\text { Secondary }\end{array}$ & & $\begin{array}{l}0.012^{* * *} \\
(0.004)\end{array}$ & $\begin{array}{l}0.011^{* *} \\
(0.004)\end{array}$ \\
\hline ODA & & $\begin{array}{l}0.000 * * * \\
(0.000)\end{array}$ & $\begin{array}{l}0.000^{* * *} \\
(0.000)\end{array}$ \\
\hline ODA (relational) & & $\begin{array}{c}0.001 \\
(0.002)\end{array}$ & $\begin{array}{c}0.002 \\
(0.002)\end{array}$ \\
\hline $\begin{array}{l}\text { GDP/capita } \\
\quad \text { (thousand US\$) }\end{array}$ & & $\begin{array}{l}0.012 * * * \\
(0.004)\end{array}$ & \\
\hline $\begin{array}{l}\text { Government } \\
\text { effectiveness }\end{array}$ & & & $\begin{array}{l}0.262^{* *} \\
(0.102)\end{array}$ \\
\hline Constant & $\begin{array}{l}3.010 * * * \\
(0.092)\end{array}$ & $\begin{array}{l}3.181 * * * \\
(0.653)\end{array}$ & $\begin{array}{l}3.282 * * * \\
(0.634)\end{array}$ \\
\hline Observations & 111 & 79 & 80 \\
\hline R-squared $\left(r^{2}\right)$ & 0.052 & 0.470 & 0.468 \\
\hline
\end{tabular}

Notes: Standard errors clustered at the county level in parentheses. ${ }^{* *} p<0.01,{ }^{* *} p<0.05,{ }^{*} p<0.1$. 
most likely because they had the financial means to introduce DRR measures in the past.

\subsection{Change in the Status of DRR Measures}

To analyse the relationship between changes in HFA scores, i.e., DRR measures, and potential explanations, first, an ordered logistic regression (ologit) was employed, which revealed several relationships (Table 3 ). A goodness of fit measure, Count $r^{2}$, and adjusted Count $r^{2}$ were employed, since they fit the data and analysis best. Thereby, the Count $r^{2}$ states how often the correct outcome would be predicted. In addition, the adjusted Count $r^{2}$ is not adjusted to the number of predictors but accounts for the most likely guess, i.e., a country would show no change. Thus, it states how much the guess improves because of the model-in contrast to the most likely guess (Williams, 2020). The models improve the correct guess by 25 to 33.3 percentage points (Table 3).

$$
\text { Count } r^{2}=\frac{\text { Number correctly classified }}{\text { Total number of cases }}
$$

\begin{tabular}{|c|c|c|}
\hline Adj. & $\begin{array}{l}\text { \# correctly } \\
\text { classified }\end{array}$ & $\begin{array}{c}\text { Max(Observed \# successes, } \\
\text { Observered \# failures) }\end{array}$ \\
\hline Count $r^{2}$ & $\begin{array}{c}\text { Total } \\
\text { \# cases }\end{array}$ & $\begin{array}{c}\text { Max(Observed \# successes, } \\
\text { Observed \# failures) }\end{array}$ \\
\hline
\end{tabular}

\subsubsection{Ordered Logistic Regression Models (ologit)}

As anticipated, the previous status is indeed negatively correlated with the likelihood for a country to be in a higher category. Countries that already score high are less likely to show progress than those that do not. The same negative relationship is identified for the number of occurrences in relation to government effectiveness. This means that the more frequent hazards occur in relation to the government's capacity, the more likely it is that a country will show negative development or no change in their DRR measures. This supports the idea that reoccurring events hinder the adoption of further measures, potentially leading to a collapse of the system. Moreover, there seems to be a negative association with the relational death tolls as well. That would mean that the higher the spike in deaths, the less likely it is that a country would be in a higher category. This is counterintuitive since one would expect that countries which experienced an event with a high death toll would rather introduce DRR measures to provide greater protection for their citizens. On the other hand, high death tolls might indicate extreme disruption that overburdened the system. The strongest positive association can be found between being in a higher category and the proportion of the population affected in interaction with the rights to participate in government selection. This finding is in line with the expectation that if large parts of the population are affected and have the opportunity to voice their views and vote, governments are more likely to introduce more advanced DRR measures. Positive relationships can also be identified for both historical damage and development aid, suggesting that countries try to prevent future financial losses if they have already experienced such losses. At the same time, ODA might be used for improving the level of DRR measures.

To check and ensure the relevance and significance of the results, we tested for violations of the parallel lines or proportional odds assumption (see the Supplementary File for Brant test results). The Brant test investigates whether the effects of the predictors are the same when the country falls into different categories of change. For instance, predictors may show a negative relationship when countries are in the negative change category, but positive if not. Although the test is overall insignificant, the Brant tests of each predictor provide evidence that the assumption that predictors are the same across categories of the dependent variable was violated. In particular, when the control on the number of reports is excluded, several predictors are below or too close to the significance threshold to discard the possibility. Indeed, several coefficients for predictors revealed not only changes in strength but also in direction.

Consequentially, the ologit results might not represent the true relationships between the predictors and the dependent variable. Therefore, in a next step, unconstrained and partially constrained generalised ordered logit (gologit) models were utilised.

\subsubsection{Generalised Ordered Logistic Regression Models (gologit)}

The gologit models relax the assumption of parallel lines for specific variables, allowing them to vary across categories of the dependent variable (as explained in Section 3.1). Table 4 details the results of the gologit models. While the assumption is relaxed for the three predictors suggested by the Brant test, the adjusted count $r^{2}$ increases and the information criteria (AIC/BIC) decrease, suggesting an increase in model fit. More unconstrained models were run in comparison and are less parsimonious according to the information criteria, although the proportion of correct guesses increases further. Consequentially, the partially constrained model (1) was chosen for interpreting the results.

Looking at the results, several significant relationships can be uncovered. First, the previous status is still highly influential regarding the likelihood that a country does not display positive change. A slightly higher previous status drastically decreases the chance to be in the positive-change category. As mentioned before, this is in line with our expectations and reflects the diminishing possibilities for strengthening DRR measures when they are already at a high level. As the investigation of the starting value revealed, development state of countries is crucial for the starting value and, thus, the previous status. The effect of the previous status is, however, 
Table 3. Results from the ologit regressions for the change in the status of DRR measures.

\begin{tabular}{|c|c|c|}
\hline \multirow{2}{*}{$\frac{\text { Variables }}{\text { Previous status }}$} & \multicolumn{2}{|c|}{$\begin{array}{c}\text { Ordered logit models } \\
\text { With/without no. of reports }\end{array}$} \\
\hline & $\begin{array}{l}-2.668 * * * \\
(0.651)\end{array}$ & $\begin{array}{l}-2.404^{* * *} \\
(0.601)\end{array}$ \\
\hline Occurrences & $\begin{array}{c}0.079 \\
(0.096)\end{array}$ & $\begin{array}{c}0.070 \\
(0.089)\end{array}$ \\
\hline Government effectiveness & $\begin{array}{c}1.208 \\
(0.771)\end{array}$ & $\begin{array}{c}1.179 \\
(0.774)\end{array}$ \\
\hline Occ. \# Gov. Eff. & $\begin{array}{l}-0.126 * * \\
(0.058)\end{array}$ & $\begin{array}{l}-0.115^{* *} \\
(0.054)\end{array}$ \\
\hline Deaths (relational) & $\begin{array}{l}-0.419 \\
(0.265)\end{array}$ & $\begin{array}{l}-0.542 * * \\
(0.239)\end{array}$ \\
\hline Damage (relational) & $\begin{array}{c}0.041 \\
(0.145)\end{array}$ & $\begin{array}{c}0.100 \\
(0.131)\end{array}$ \\
\hline Affected (rel. population) & $\begin{array}{l}11.829 * * \\
(4.658)\end{array}$ & $\begin{array}{l}9.955^{* *} \\
(4.223)\end{array}$ \\
\hline Voice \& Accountabilty & $\begin{array}{c}0.025 \\
(0.720)\end{array}$ & $\begin{array}{c}0.071 \\
(0.674)\end{array}$ \\
\hline Affec. (rel.pop.) \# V\&A & $\begin{array}{l}9.698^{*} \\
(5.336)\end{array}$ & $\begin{array}{l}10.427^{* *} \\
(4.911)\end{array}$ \\
\hline Occurrences (hist.) & $\begin{array}{c}-0.012 \\
(0.011)\end{array}$ & $\begin{array}{r}-0.013 \\
(0.011)\end{array}$ \\
\hline Deaths (hist.) (ts.) & $\begin{array}{c}-0.004 \\
(0.014)\end{array}$ & $\begin{array}{r}-0.000 \\
(0.013)\end{array}$ \\
\hline Damage (hist.) (billion US\$) & $\begin{array}{l}0.029 * * * \\
(0.008)\end{array}$ & $\begin{array}{l}0.027^{* * *} \\
(0.008)\end{array}$ \\
\hline Affec. (hist.) (million) & $\begin{array}{c}-0.002 \\
(0.001)\end{array}$ & $\begin{array}{c}-0.001 \\
(0.001)\end{array}$ \\
\hline School enrolment Primary & $\begin{array}{l}-0.006 \\
(0.027)\end{array}$ & $\begin{array}{l}-0.008 \\
(0.028)\end{array}$ \\
\hline School enrolment Secondary & $\begin{array}{c}0.030 * \\
(0.018)\end{array}$ & $\begin{array}{c}0.024 \\
(0.019)\end{array}$ \\
\hline ODA & $\begin{array}{l}0.001^{* *} \\
(0.000)\end{array}$ & $\begin{array}{c}0.001^{*} \\
(0.000)\end{array}$ \\
\hline ODA (relational) & $\begin{array}{c}-0.133^{* *} \\
(0.060)\end{array}$ & $\begin{array}{c}-1.01^{* *} \\
(0.050)\end{array}$ \\
\hline 3 reports submitted & $\begin{array}{c}-0.948 \\
(0.777)\end{array}$ & \\
\hline 4 reports submitted & $\begin{array}{r}-0.098 \\
(0.655)\end{array}$ & \\
\hline /cut1 & $\begin{array}{c}-7.347^{* *} \\
(3.593)\end{array}$ & $\begin{array}{c}-7.311^{* *} \\
(3.281)\end{array}$ \\
\hline /cut2 & $\begin{array}{c}-3.744 \\
(3.451)\end{array}$ & $\begin{array}{r}-3.763 \\
(3.200)\end{array}$ \\
\hline Observations & 110 & 110 \\
\hline Log pseudolikelihood it. 0 & -107.2 & -107.2 \\
\hline Log pseudolikelihood & -81.71 & -82.99 \\
\hline Clusters & 64 & 64 \\
\hline Count $r^{2}$ & 0.696 & 0.661 \\
\hline Adjusted Count $r^{2}$ & 0.333 & 0.255 \\
\hline
\end{tabular}

Notes: Standard errors clustered at the county level in parentheses. ${ }^{* * *} \mathrm{p}<0.01,{ }^{* *} \mathrm{p}<0.05,{ }^{*} \mathrm{p}<0.1$. 
Table 4. Results from the generalised ordered logit (gologit) regression models.

\begin{tabular}{|c|c|c|c|c|c|c|}
\hline \multirow{2}{*}{$\frac{\text { Unconstrained: }}{\text { Variable }}$} & \multicolumn{2}{|c|}{$\begin{array}{l}\text { Partially constrained (1) } \\
\text { Occ; death_rel; occ_hist }\end{array}$} & \multicolumn{2}{|c|}{$\begin{array}{l}\text { Partially constrained ( } 2 \text { ) } \\
\text { All hazard predictors }\end{array}$} & \multicolumn{2}{|c|}{$\begin{array}{l}\text { Unconstrained gologit } \\
\text { All predictors }\end{array}$} \\
\hline & Coeff. & Marg. Eff. & Coeff. & Marg. Eff. & Coeff. & Marg. Eff. \\
\hline \multicolumn{7}{|l|}{ Previous Status } \\
\hline Negative & $-2.729 * * *$ & 0.021 & $-2.939 * * *$ & 0.000 & $-1.470^{*}$ & 0.000 \\
\hline Negligible & $-2.729 * * *$ & $0.651 * * *$ & $-2.939 * * *$ & 0.452 & $-3.596 * * *$ & $0.659 *$ \\
\hline Positive & & $-0.673 * * *$ & & -0.452 & & $-0.659 *$ \\
\hline \multicolumn{7}{|l|}{ Occurrences } \\
\hline Negative & 0.243 & -0.001 & 0.254 & -0.000 & $0.328 *$ & -0.000 \\
\hline Negligible & -0.021 & 0.021 & -0.073 & 0.024 & -0.110 & 0.030 \\
\hline Positive & & -0.019 & & -0.024 & & -0.030 \\
\hline \multicolumn{7}{|l|}{ Governance Eff. } \\
\hline Negative & $1.518^{*}$ & 0.005 & $1.711^{* *}$ & 0.000 & $2.596^{*}$ & 0.000 \\
\hline Negligible & $1.518^{*}$ & 0.005 & $1.711^{* *}$ & 0.000 & $2.596 *$ & 0.000 \\
\hline Positive & & -0.154 & & -0.215 & & -0.249 \\
\hline \multicolumn{7}{|c|}{ Occurrences \# Gov. Eff. } \\
\hline Negative & $-0.225^{* * *}$ & & -0.179 & & -0.323 & \\
\hline Negligible & $-0.225^{* * *}$ & & $-0.326 * * *$ & & $-0.216^{* *}$ & \\
\hline \multicolumn{7}{|l|}{ Deaths (rel.) } \\
\hline Negative & 2.248 & -0.017 & 1.705 & -0.000 & 2.325 & -0.000 \\
\hline Negligible & $-1.501 * * *$ & $0.387^{* * *}$ & $-1.903 * * *$ & $0.293^{*}$ & $-1.946 * * *$ & 0.356 \\
\hline Positive & & $-0.370 * * *$ & & $-0.293^{*}$ & & $-0.356 * *$ \\
\hline \multicolumn{7}{|l|}{ Damage (rel.) } \\
\hline Negative & $0.047^{* * *}$ & -0.000 & $0.100 *$ & -0.000 & 0.147 & -0.000 \\
\hline Negligible & $0.342^{*}$ & $-0.082^{*}$ & $0.482 * *$ & -0.074 & $0.525^{*}$ & -0.096 \\
\hline Positive & & $0.084^{*}$ & & 0.074 & & $0.096 *$ \\
\hline \multicolumn{7}{|c|}{ Affected (rel. pop.) } \\
\hline Negative & $11.183^{* * *}$ & -0.112 & $18.595^{*}$ & -0.000 & 23.692 & -0.000 \\
\hline Negligible & $11.183^{* * *}$ & $-3.437^{* *}$ & 8.094 & -1.737 & $8.952 *$ & -2.188 \\
\hline Positive & & $3.549 * *$ & & 1.738 & & 2.188 \\
\hline \multicolumn{7}{|c|}{ Voice \& Accountability } \\
\hline Negative & 0.070 & -0.006 & 0.161 & -0.000 & -0.134 & -0.000 \\
\hline Negligible & 0.070 & -0.174 & 0.147 & -0.123 & 0.763 & -0.252 \\
\hline Positive & & 0.180 & & 0.123 & & 0.252 \\
\hline \multicolumn{7}{|c|}{ Affec. (re.) \# V\&A } \\
\hline Negative & $11.020 * *$ & & 15.153 & & 25.647 & \\
\hline Negligible & $11.020 * *$ & & $10.966 *$ & & $10.258^{*}$ & \\
\hline \multicolumn{7}{|c|}{ Occurrences (hist.) } \\
\hline Negative & -0.027 & 0.000 & $-0.063^{*}$ & 0.000 & $-0.086^{* *}$ & 0.000 \\
\hline Negligible & -0.006 & 0.001 & 0.020 & -0.003 & 0.017 & -0.003 \\
\hline Positive & & -0.002 & & 0.003 & & 0.003 \\
\hline \multicolumn{7}{|c|}{ Deaths (hist.) (ts.) } \\
\hline Negative & -0.001 & 0.000 & -0.009 & 0.000 & 0.015 & -0.000 \\
\hline Negligible & -0.001 & 0.000 & -0.016 & 0.002 & -0.003 & 0.001 \\
\hline Positive & & -0.000 & & -0.002 & & -0.001 \\
\hline \multicolumn{7}{|c|}{ Damage (hist.) (bill. US\$) } \\
\hline Negative & $0.047^{* * *}$ & -0.000 & $0.100 *$ & -0.000 & 0.147 & -0.000 \\
\hline Negligible & $0.047 * * *$ & $-0.011 * * *$ & -0.004 & 0.001 & -0.010 & 0.002 \\
\hline Positive & & $0.011^{* * *}$ & & -0.001 & & -0.002 \\
\hline \multicolumn{7}{|c|}{ School enrolment primary } \\
\hline Negative & -0.012 & 0.000 & -0.034 & 0.000 & $-0.198 * *$ & 0.000 \\
\hline Negligible & -0.012 & 0.003 & -0.034 & 0.005 & -0.001 & 0.000 \\
\hline Positive & & -0.003 & & -0.005 & & -0.000 \\
\hline
\end{tabular}


Table 4. (Cont.) Results from the generalised ordered logit (gologit) regression models.

\begin{tabular}{|c|c|c|c|c|c|c|}
\hline \multirow{2}{*}{$\frac{\text { Unconstrained: }}{\text { Variable }}$} & \multicolumn{2}{|c|}{$\begin{array}{l}\text { Partially constrained (1) } \\
\text { Occ; death_rel; occ_hist }\end{array}$} & \multicolumn{2}{|c|}{$\begin{array}{l}\text { Partially constrained ( } 2 \text { ) } \\
\text { All hazard predictors }\end{array}$} & \multicolumn{2}{|c|}{$\begin{array}{l}\text { Unconstrained gologit } \\
\text { All predictors }\end{array}$} \\
\hline & Coeff. & Marg. Eff. & Coeff. & Marg. Eff. & Coeff. & Marg. Eff. \\
\hline \multicolumn{7}{|l|}{ School enrolment secondary } \\
\hline Negative & 0.031 & -0.000 & $0.045^{* *}$ & -0.000 & 0.058 & -0.000 \\
\hline Negligible & 0.031 & -0.007 & $0.045^{* *}$ & -0.007 & $0.051^{*}$ & -0.009 \\
\hline Positive & & 0.008 & & 0.007 & & 0.009 \\
\hline \multicolumn{7}{|l|}{ ODA } \\
\hline Negative & $0.001 * *$ & -0.000 & $0.001^{*}$ & -0.000 & 0.001 & -0.000 \\
\hline Negligible & $0.001 * *$ & $-0.000 *$ & $0.001^{*}$ & -0.000 & $0.001 * *$ & -0.000 \\
\hline Positive & & $0.000 * *$ & & 0.000 & & 0.000 \\
\hline \multicolumn{7}{|l|}{ ODA (rel.) } \\
\hline Negative & $-0.148 * *$ & 0.001 & $-0.148 * *$ & 0.000 & 0.989 & -0.000 \\
\hline Negligible & $-0.148 * *$ & $0.035^{* *}$ & $-0.148^{* *}$ & 0.023 & $-0.154 * *$ & $0.028 *$ \\
\hline Positive & & $-0.036^{* *}$ & & -0.023 & & $-0.028 *$ \\
\hline \multicolumn{7}{|l|}{ \# of reports: 2} \\
\hline Negative & 0.046 & & 0.094 & & -1.140 & \\
\hline Negligible & 0.046 & & -0.491 & & -0.323 & \\
\hline \multicolumn{7}{|l|}{ \# of reports: 3} \\
\hline Negative & -0.962 & & -0.914 & & -0.487 & \\
\hline Negligible & -0.962 & & -0.910 & & -1.241 & \\
\hline \# of reports: 4 & (omitted) & & (omitted) & & (omitted) & \\
\hline \multicolumn{7}{|l|}{ Constant } \\
\hline Negative & $8.881^{* *}$ & & $10.813^{* * *}$ & & $20.731^{* * *}$ & \\
\hline Negligible & 6.650 & & $8.327^{* *}$ & & $6.944^{*}$ & \\
\hline Observations & 112 & 112 & 112 & 112 & 112 & 112 \\
\hline Clusters & 64 & 64 & 64 & 64 & 64 & 64 \\
\hline Pseudo Log-Likelihood: Iteration 0 & -107.2 & -107.2 & -107.2 & -107.2 & -107.2 & -107.2 \\
\hline Pseudo Log-Likelihood & -74.51 & -74.51 & -68.95 & -68.95 & -63.88 & -63.88 \\
\hline$r^{2}$ & 0.305 & 0.305 & 0.357 & 0.357 & 0.404 & 0.404 \\
\hline Count $r^{2}$ & \multicolumn{2}{|c|}{0,696} & \multicolumn{2}{|c|}{0,75} & \multicolumn{2}{|c|}{0,75} \\
\hline Adjusted Count $r^{2}$ & \multicolumn{2}{|c|}{0,333} & \multicolumn{2}{|c|}{0,451} & \multicolumn{2}{|c|}{0,451} \\
\hline AIC & \multicolumn{2}{|c|}{197} & \multicolumn{2}{|c|}{206} & \multicolumn{2}{|c|}{208} \\
\hline $\mathrm{AIC} / \mathrm{N}$ & \multicolumn{2}{|c|}{1,759} & \multicolumn{2}{|c|}{1,838} & \multicolumn{2}{|c|}{1,855} \\
\hline $\mathrm{BIC}$ & \multicolumn{2}{|c|}{262} & \multicolumn{2}{|c|}{298} & \multicolumn{2}{|c|}{317} \\
\hline
\end{tabular}

Notes: ${ }^{* *} \mathrm{p}<0.01,{ }^{* *} \mathrm{p}<0.05,{ }^{*} \mathrm{p}<0.1$.

insignificant when the country falls into the negative change category. For experiencing a decrease in the status of DRR measures, it does not seem to matter how high the previous status was.

Second, governance effectiveness can enhance the probability to be in a higher category, but the effect is diminished as hazardous events become more frequent. This supports the theory that frequent hazard events can overburden the governmental apparatus, potentially leading to a collapse of the system. Vice versa, an effective government might compensate for and offset infrequent small-scale occurrences. Thus, changes in DRR measures are likely to be adopted for a low number of recurring occurrences. Unfortunately, the analysis is not able to confirm whether these are incremental changes or due to shocks.
Third, and most interestingly, there seems to be a strong positive association in the interaction of the number of people affected and the voice and accountability mechanisms which exist in the country. This effect would, in fact, confirm Sen's logic in disaster studies and support the findings of Aldrich et al. (2019) that the affected population assign responsibility for the damage caused by hazardous events to the incumbent government. Thus, in a country with higher levels of civil liberties and political rights and some degree of independent media as a monitor of government, politicians adopt more DRR measures to placate their voters, leading to a positive development in national DRR, following extreme hazard events that affected large proportions of the population. Accordingly, the larger the proportion of the population affected, the stronger the effect is likely to be. 
Fourth, spikes in death tolls seem to have a negative association with a country being in the positive-change category. Since spikes in death tolls indicate devastating events disrupting the system, these events not only seem to affect the country adversely but also inhibit positive change. In contrast, extraordinary levels of damage caused by hazards seem to be conducive for a country to introduce positive change in their DRR measures. Thus, countries may have reacted to extreme financial losses by increasing their DRR measures. This finding might be interesting for the argument that death tolls and damage are not interchangeable measures of severity since they have dissimilar effects. For the theory of external shocks, financial losses seem to be more conducive to positive change than human losses. One caveat to be mentioned is that, since reporting periods span several years, it is impossible to say whether the improvements occurred in preparation before-and were futile-or if they were a reaction to a particular disaster. Before relying on this finding, in-depth cases studies should investigate these occurrences and establish the temporal connection between events and change in DRR measures.

Fifth, experiences of damage in the past further increase the likelihood of a country being in a higher category. One explanation for this could be that such countries would have had a lower status of DRR measures in the past, but now are incentivised to establish more measures. Reasons for this should be investigated further. Lastly, more development aid is likewise associated with a higher likelihood of being in a higher category, indicating that aid is indeed helpful for countries to advance their DRR measures and, thus, their preparedness. However, marginal effects are considerably low suggesting that large sums are necessary to spur this trend. The relational ODA confirms that rises in development aid are rather associated with being in lower categories. This might be because countries that have to rely more on development aid than in the past are occupied with different issues or are, in fact, recovering from some kind of disaster. In contrast, if reliance on aid were able to be reduced, this would probably be due to either the country having advanced over the last three years and no longer needing the same amount of aid whilst also improving its DRR measures, or alternatively, due to the country having recovered from a disaster during the reporting period.

To confirm the findings with robustness checks, the models were also run as multinomial logit (mlogit), ordinal generalised linear (oglm), OLS regressions models with ordinal dependent variable. The main findings do not change, and effects are confirmed across the models.

\section{Conclusions}

This study marks an empirical attempt to explain the changes in the national status of DRR measures on a global scale with prominent theories of policy change. It utilises data from the HFA on the four reporting periods between 2005 and 2015 and combines it with data on disasters from EM-DAT and governance retrieved from the Quality of Governance dataset.

First, a brief investigation revealed that high starting values of DRR measures are correlated with higher levels of wealth and development. Then, controlling for the bias of a high previous status, generalised ordered logit models were utilised to test the theoretical hypotheses and were checked by a battery of different models. In line with theoretical explanations, the findings indicate relationships between several predictors and the change in a country's DRR measures. There is a positive effect of government effectiveness, which is offset by frequent natural hazard events. While extraordinary damage facilitates positive change, extremely deadly events are surprisingly associated with little positive change. Furthermore, the larger the proportion of the population affected, the more likely it is that positive change is introduced. This effect is even supported by voice and accountability mechanisms which promote the adoption of more expansive DRR measures. In addition, development aid can also be conducive for facilitating positive change.

This study found support for all three employed theoretical perspectives on policy change. In the case of DRR, incremental change may be adopted if hazards occur frequently and if authorities are not overburdened. External shocks in terms of damage and the proportion of the population affected seem to spur positive change. Even accountability mechanisms are helpful for positive change in the status of DRR measures.

However, there are some limitations to this study offering avenues for future research. First, the results have been limited to the available self-reported data on DRR measures. Thereby, the focus was on natural hazards and their impact. Future research could emphasise biological or technological hazards or integrate the various hazard types. Looking at the Sendai Framework as the successor of the HFA, Cutter and Gall (2015) expressed concerns about the indicators even at its inception. Issues identified included insufficient monitoring, the availability of reliable loss data, and the understanding of the socioeconomic impacts, let alone the ambiguity of baselines (Cutter \& Gall, 2015). Even a quick glance at the Sendai Framework Monitor (UNDRR, 2019) confirms the need for caution since, as yet, there are too few national submissions to conduct large-n analyses.

Second, there are other theoretical explanations, which have not been included in this analysis, yet provide distinct opportunities for future research. Future studies should try to integrate the effects of learning and knowledge diffusion to a larger extent. Spillover effects are capable of transporting experience and knowledge across national borders, and, thus, can lead to policy transfer and diffusion of policy innovation without an actual event (Aldrich et al., 2019; Benson \& Jordan, 2011; Berry \& Berry, 1990; Dobbin, Simmons, \& Garrett, 2007; Dolowitz \& Marsh, 2000; Tosun \& Croissant, 2016). Globalised mass media might yet be another facilitat- 
ing factor transporting impacts from the event location to other parts of the world (Wittneben, 2012), although geographical proximity might strengthen the effect (Nohrstedt \& Weible, 2010). In addition, a careful look at policy processes unfolding between the event occurrence and policy change might further contribute greatly to future research findings. This could include aspects such as policy entrepreneurship and advocacy coalitions (Mintrom \& Norman, 2009; Nohrstedt \& Weible, 2010; Rhodes \& 't Hart, 2014; Shipan \& Volden, 2008 ) in the analysis of policy change in DRR.

\section{Acknowledgments}

The author thanks the editors and anonymous referees for their detailed and constructive comments. Furthermore, he is grateful to Karl-Oskar Lindgren for insightful feedback on an earlier version of the article. Thanks go also to the supervisors Daniel Nohrstedt and Charles Parker for their constructive feedback and thoughts during the process. This research was supported by the Centre of Natural Hazards and Disaster Science (CNDS).

\section{Conflict of Interests}

The author declares no conflict of interests.

\section{Supplementary Material}

Supplementary material for this article is available online in the format provided by the author (unedited).

\section{References}

Adger, W. N., Quinn, T., Lorenzoni, I., Murphy, C., \& Sweeney, J. (2013). Changing social contracts in climate-change adaptation. Nature Climate Change, 3(4), 330-333. https://doi.org/10.1038/nclimate 1751

Aldrich, D. P., Forester, S., \& Horhager, E. (2019). Triggers for policy change: The 3.11 Fukushima meltdowns and nuclear policy continuity. Environmental Politics, 28(7), 1214-1235. https://doi.org/10.1080/ 09644016.2018 .1510216

Baumgartner, F. R., Jones, B. D., \& Wilkerson, J. D. (2002). Studying policy dynamics. In F. R. Baumgartner \& B. D. Jones (Eds.), Policy dynamics (pp. 29-46). Chicago, IL: University of Chicago Press.

Benson, D., \& Jordan, A. (2011). What have we learned from policy transfer research? Dolowitz and Marsh revisited. Political Studies Review, 9(3), 366-378. https://doi.org/10.1111/j.1478-9302.2011.00240.x

Berry, F., \& Berry, W. (1990). State lottery adoptions as policy innovations: An event history analysis. American Political Science Review, 84(2), 395-415. https:// doi.org/10.2307/1963526

Birkland, T. A. (2016). Policy process theory and natural hazards (Vol. 1). Oxford: Oxford University Press. https://doi.org/10.1093/acrefore/ 9780199389407.013.75

Boin, A., \& 't Hart, P. (2003). Public leadership in times of crisis: Mission impossible? Public Administration Review, 63(5), 544-553. https://doi-org.ezproxy.its. uu.se/10.1111/1540-6210.00318

Boin, A., \& 't Hart, P. (2010). Organising for effective emergency management: Lessons from research. Australian Journal of Public Administration, 69(4), 357-371. https://doi.org/10.1111/j.14678500.2010.00694.x

Boin, A., 't Hart, P., \& McConnell, A. (2009). Crisis exploitation: Political and policy impacts of framing contests. Journal of European Public Policy, 16(1), 81-106. https://doi.org/10.1080/ 13501760802453221

Brant, R. (2016). Assessing proportionality in the proportional odds model for ordinal logistic regression. Biometrics, 46(4), 1171-1178.

Brody, S. D. (2003). Are we learning to make better plans?3 A longitudinal analysis of plan quality associated with natural hazards. Journal of Planning Education and Research, 23(2), 191-201. https://doi.org/ 10.1177/0739456X03258635

Brody, S. D., Zahran, S., Highfield, W. E., Bernhardt, S. P., \& Vedlitz, A. (2009). Policy learning for flood mitigation: A longitudinal assessment of the community rating system in Florida. Risk Analysis, 29(6), 912-929. https://doi.org/10.1111/j.1539-6924.2009.01210.x

Centre for Research on the Epidemiology of Disasters. (2009). EM-DAT: The international disaster database. EM-DAT. Retrieved from http://www. emdat.be/Database

Collier, R. B., \& Collier, D. (1991). Shaping the political arena: Critical junctures, the labor movement, and regime dynamics in Latin America. Princeton, NJ: Princeton University Press.

Cutter, S. L., \& Gall, M. (2015). Sendai targets at risk. Nature Climate Change, 5(8), 707-709. https://doi. org/10.1038/nclimate2718

Dekker, S., \& Hansén, D. (2004). Learning under pressure: The effects of politicization on organizational learning in public bureaucracies. Journal of Public Administration Research and Theory, 14(2), 211-230. https:// doi.org/10.1093/jopart/muh014

Dolowitz, D. P., \& Marsh, D. (2000). Learning from abroad: The role of policy transfer in contemporary policy-making. Governance, 13(1), 5-23. https://doi. org/10.1111/0952-1895.00121

Di Baldassarre, G., Nohrstedt, D., Mård, J., Burchardt, S., Albin, C., Bondesson, S., . . . Parker, C. F. (2018). An integrative research framework to unravel the interplay of natural hazards and vulnerabilities. Earth's Future, 6(3), 305-310. https://doi.org/ 10.1002/2017EF000764

Dobbin, F., Simmons, B., \& Garrett, G. (2007). The global diffusion of public policies: Social construction, coer- 
cion, competition, or learning? Annual Review of Sociology, 33(1), 449-472. https://doi.org/10.1146/ annurev.soc.33.090106.142507

Fullerton, A. S., \& Dixon, J. C. (2010). Generational conflict or methodological artifact? Reconsidering the relationship between age and policy attitudes in the U.S., 1984-2008. Public Opinion Quarterly, 74(4), 643-673. https://doi.org/10.1093/poq/nfq043

Hayes, M. (2017). Incrementalism and public policymaking. Policy, Administration, and Bureaucracy, 1-24. https://doi.org/10.1093/acrefore/ 9780190228637.013.133

Jones, B. D., \& Baumgartner, F. R. (2012). From there to here: Punctuated equilibrium to the general punctuation thesis to a theory of government information processing. Policy Studies Journal, 40(1), 1-20. https://doi.org/10.1111/j.1541-0072.2011.00431.x

Koivisto, J. E., \& Nohrstedt, D. (2017). A policymaking perspective on disaster risk reduction in Mozambique. Environmental Hazards, 16(3), 210-227. https://doi. org/10.1080/17477891.2016.1218820

Krasner, S. D. (1984). Approaches to the state: Alternative conceptions and historical dynamics. Comparative Politics, 16(2), 223-246.

Lindblom, C. E. (1959). The science "muddling" through. Public Administration Review, 19(2), 79-88.

Lindeboom, M., \& Van Doorslaer, E. (2004). Cut-point shift and index shift in self-reported health. Journal of Health Economics, 23(6), 1083-1099. https://doi. org/10.1016/j.jhealeco.2004.01.002

Long, J. S., \& Freese, J. (2014). Regression models for categorical dependent variables using stata ( $3 \mathrm{rd}$ ed.). College Station, TX.: Stata Press.

Mileti, D. S., \& Brien, P. W. O. (1992). Warnings during disaster: Normalizing communicated risk. Social Problems, 39(1), 40-57.

Mintrom, M., \& Norman, P. (2009). Policy entrepreneurship and policy change. Policy Studies Journal. https://doi.org/10.1111/j.1541-0072.2009.00329.x

Muller, B., \& Schulte, S. (2011). Governing wildfire risks: What shapes county hazard mitigation programs? Journal of Planning Education and Research, 31(1), 60-73. https://doi.org/10.1177/0739456X10395895

Nohrstedt, D., \& Nyberg, L. (2015). Do floods drive hazard mitigation policy? Evidence from Swedish municipalities. Geografiska Annaler, Series A: Physical Geography, 97(1), 109-122. https://doi.org/10.1111/geoa. 12081

Nohrstedt, D., \& Weible, C. M. (2010). The logic of policy change after crisis: Proximity and subsystem interaction. Risk, Hazards \& Crisis in Public Policy, 1(2), 1-32. https://doi.org/10.2202/1944-4079.1035

Olson, R. S. (2000). Toward a politics of disaster: Losses, values, agendas and blame. International Journal of Mass Emergencies and Disasters, 18(2), 265-287.

Pierson, P. (2000). Not just what, but when: Timing and sequence in political processes. Studies in American Political Development, 14(1), 72-92. https://doi.org/

\section{$10.1017 / \mathrm{S} 0898588 \times 00003011$}

Rhodes, R. A. W., \& 't Hart, P. (Eds.). (2014). The Oxford handbook of political leadership. Oxford: Oxford University Press. https://doi.org/10.1093/oxfordhb/ 9780199653881.001.0001

Russell, L., James, G. D., \& Bourque, L. B. (1995). Preparedness and hazard mitigation actions before and after two earthquakes. Environment and Behavior, 27(6), 744-770.

Schneider, U., Pfarr, C., Schneider, B. S., \& Ulrich, V. (2012). I feel good! Gender differences and reporting heterogeneity in self-assessed health. European Journal of Health Economics, 13(3), 251-265. https:// doi.org/10.1007/s10198-011-0301-7

Sen, A. (2001). Development as freedom. Oxford: Oxford University Press.

Shipan, C., \& Volden, C. (2008). The mechanisms of policy diffusion. American Journal of Political Science, 52(4), 840-857. https://doi.org/10.1111/ j.1540-5907.2008.00346.x

Stark, A. (2018). New institutionalism, critical junctures and post-crisis policy reform. Australian Journal of Political Science, 53(1), 24-39. https://doi.org/ 10.1080/10361146.2017.1409335

Teorell, J., Dahlberg, S., Holmberg, S., Rothstein, B., Pachon, N. A., \& Axelsson, S. (2020a). The QOG standard dataset codebook, version Jan20. Gothenburg: The Quality of Government Institute of the University of Gothenburg.

Teorell, J., Dahlberg, S., Holmberg, S., Rothstein, B., Pachon, N. A., \& Axelsson, S. (2020b). The quality of government standard dataset, version Jan20. Gothenburg: The Quality of Government Institute of the University of Gothenburg.

Tosun, J., \& Croissant, A. (2016). Policy diffusion: A regime-sensitive conceptual framework. Global Policy, 7(4), 534-540. https://doi.org/10.1111/17585899.12363

United Nations International Strategy for Disaster Reduction. (2005). Hyogo Framework for Action 2005-2015: Building the resilience of nations, world conference on disaster reduction (A/CONF.206/6) $\S$ (2005). Kobe: United Nations International Strategy for Disaster Reduction. Retrieved from https://www.preventionweb.net/files/17671_ finalreportconference1.pdf

United Nations Office for Disaster Risk Reduction. (n.d.). PreventionWeb: HFA national progress query tool. PreventionWeb. Retrieved from https://www. preventionweb.net/applications/hfa/qbnhfa/home

United Nations Office for Disaster Risk Reduction. (2019). Sendai framework monitor. UNDRR. Retrieved from https://sendaimonitor.undrr.org/analytics/globaltargets/13

Wanner, M. S. T. (2020). The effectiveness of soft law in international environmental regimes: Participation and compliance in the Hyogo Framework for Action. International Environmental Agreements: 
Politics, Law and Economics, 1-20. https://doi.org/ 10.1007/s10784-020-09490-8

Williams, R. (2006). Generalized ordered logit/partial proportional odds models for ordinal dependent variables. Stata Journal, 6(1), 58-82. https://doi.org/ $10.1177 / 1536867 \times 0600600104$

Williams, R. (2016). Understanding and interpreting generalized ordered logit models. Journal of Mathematical Sociology, 40(1), 7-20. https://doi.org/10.1080/ 0022250X.2015.1112384

Williams, R. (2020). Scalar measures of fit: Pseudo $R 2$ and information measures (AIC \& BIC). Notre
Dame, IN: University of Notre Dame. Retrieved from https://www3.nd.edu/ rwilliam/stats3/L05.pdf

Wittneben, B. B. F. (2012). The impact of the Fukushima nuclear accident on European energy policy. Environmental Science \& Policy, 15(1), 1-3. https://doi.org/ 10.1016/J.ENVSCI.2011.09.002

Zahran, S., Brody, S. D., Vedlitz, A., Grover, H., \& Miller, C. (2008). Vulnerability and capacity: Explaining local commitment to climate-change policy. Environment and Planning C: Government and Policy, 26(3), 544-562. https://doi.org/10.1068/c2g

\section{About the Author}

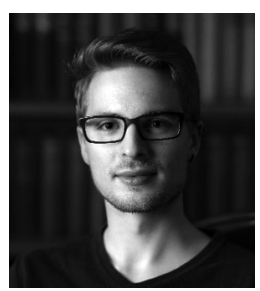

Maximilian S. T. Wanner is a Doctoral Student at the Department of Government, Uppsala University, and is affiliated with the Centre of Natural Hazards and Disaster Science (CNDS). His dissertation project focuses on the effectiveness of international regimes in disaster risk reduction and their effect on national disaster governance. He is the PhD Student Representative on the board of the CNDS. 